Article

\title{
Commensal Bacterium Rothia aeria Degrades and Detoxifies Gluten via a Highly Effective Subtilisin Enzyme
}

\author{
Guoxian Wei ${ }^{1, * \mathbb{D}}$, Ghassan Darwish ${ }^{1, \dagger}$, Frank G. Oppenheim ${ }^{1}$, Detlef Schuppan ${ }^{2,3, *, \ddagger}$ \\ and Eva J. Helmerhorst ${ }^{1, \ddagger}$ \\ 1 Department of Molecular and Cell Biology, Henry M. Goldman School of Dental Medicine, 700 Albany Street, \\ Boston, MA 20118, USA; gdarwish@bu.edu (G.D.); fropp@bu.edu (F.G.O.); histatins@gmail.com (E.J.H.) \\ 2 Institute for Translational Immunology and Research Center for Immunotherapy (FZI), \\ Johannes Gutenberg University (JGU) Medical Center, 5513 Mainz, Germany \\ 3 Division of Gastroenterology, Beth Israel Deaconess Medical Center, Harvard Medical School, \\ Boston, MA 02215, USA \\ * Correspondence: weigx@bu.edu (G.W.); detlef.schuppan@unimedizin-mainz.de (D.S.); \\ Tel.: +49-6131-17-7355 (ext. 7355) (D.S.) \\ + Current Affiliation: Department of Oral and Maxillofacial Surgery, School of Dentistry, \\ King Abdulaziz University, Jeddah 21589, Saudi Arabia. \\ $\ddagger \quad$ D.S. and E.J.H. share senior authorship.
}

Received: 1 November 2020; Accepted: 30 November 2020; Published: 2 December 2020 updates

\begin{abstract}
Celiac disease is characterized by a chronic immune-mediated inflammation of the small intestine, triggered by gluten contained in wheat, barley, and rye. Rothia aeria, a gram-positive natural colonizer of the oral cavity and the upper digestive tract is able to degrade and detoxify gluten in vitro. The objective of this study was to assess gluten-degrading activity of live and dead R. aeria bacteria in vitro, and to isolate the R. aeria gluten-degrading enzyme. Methods: After an overnight fast, Balb/c mouse were fed a $1 \mathrm{~g}$ pellet of standard chow containing $50 \%$ wheat (and $4 \%$ gliadin) with or without $1.6 \times 10^{7}$ live R. aeria bacteria. After $2 \mathrm{~h}$, in vivo gluten degradation was assessed in gastric contents by SDS-PAGE and immunoblotting, and immunogenic epitope neutralization was assessed with the R5 gliadin ELISA assay. R. aeria enzyme isolation and identification was accomplished by separating proteins in the bacterial cell homogenate by C18 chromatography followed by gliadin zymography and mass spectrometric analysis of excised bands. Results: In mice fed with R. aeria, gliadins and immunogenic epitopes were reduced by $20 \%$ and $33 \%$, respectively, as compared to gluten digested in control mice. Killing of $R$. aeria bacteria in ethanol did not abolish enzyme activity associated with the bacteria. The gluten degrading enzyme was identified as BAV86562.1, here identified as a member of the subtilisin family. Conclusion: This study shows the potential of $R$. aeria to be used as a first probiotic for gluten digestion in vivo, either as live or dead bacteria, or, alternatively, for using the purified R. aeria enzyme, to benefit the gluten-intolerant patient population.
\end{abstract}

Keywords: celiac disease; epitope; Rothia; Bacillus; gluten; degradation; subtilisin; commensal; detoxify; neutralize; cure

\section{Introduction}

Gluten is found in wheat, barley, and rye and triggers celiac diseases (CeD), a chronic inflammatory immune-mediated disease affecting the (proximal) small intestine [1]. Globally, $\mathrm{CeD}$ can be found in 0.5 up to $2 \%$ of wheat consuming populations [2]. Immunogenic gluten proteins show an unusual 
resistance to degradation by human digestive enzymes and are antigenically presented on human leukocyte antigen (HLA) DQ2 or DQ8 that are expressed on myeloid and B cells in the intestinal lamina propria, triggering a gluten peptide specific T helper 1 (Th1) T cell response [3,4]. Immunogenicity (toxicity) associated with gluten is peptide length-dependent, where peptides shorter than 9 residues are unable to generate an immune response [5-7]. Therefore, detoxification of gluten peptides can be achieved by their extensive proteolytic fragmentation to smaller gluten moieties.

The microbiome colonizing the oral cavity is a rich source of proteolytic enzymes. The oral cavity is also the port of entry where ingested food contents are mixed with saliva and reach the more downstream regions of the gastrointestinal tract. The oral microbiome comprises over 700 different microbial species or phenotypes [8,9]. Saliva harbors over 100 million bacterial cells per milliliter. In fact, the oral cavity is, after the colon and the cecum, the most densely colonized part of the human gastrointestinal tract [10]. The functions and properties of many individual species within these mixed culture microbiomes remain unknown. Furthermore, the potential contribution of, e.g., oral microbial species to physiological processes in the digestive tract is virtually unknown.

We recently showed that oral Rothia bacteria produce enzymes that degrade dietary gluten proteins in vitro [3]. This finding of an oral (and gastric) microbe digesting an essential food constituent points to potentially novel functions for oral microorganisms in digestion, having implications beyond the oral cavity. The Rothia genus, formerly called Stomatococcus, comprises several species, including $R$. aeria, R. mucilaginosa, and R. dentocariosa. They are Gram-positive microbes that thrive well in the oral environment. R. mucilaginosa has also been detected at low levels in the duodenum [11]. Little is known on the functional role that Rothia species play in the oral cavity, other than that they are mostly associated with oral health [12]. Here, the discovery of the gluten-degrading capabilities of Rothia bacteria added to the potential beneficial activity of this commensal. Furthermore, the fact that R. mucilaginosa and R. aeria species [13-15] degrade gluten suggests they may be useful in the treatment of $\mathrm{CeD}$, which is triggered by incompletely digested gluten peptides.

The purpose of the present study was three-fold. First, to investigate the gluten degrading and epitope neutralizing activity of $R$. aeria in vivo; second, to assess if $R$. aeria bacteria would retain enzymatic activity after the bacteria are killed; and third, to isolate and identify the gluten-degrading enzyme from R. aeria.

\section{Materials and Methods}

\subsection{In Vivo Digestion Experiment}

Cultivation of R. aeria bacteria-Rothia aeria strain WSA-8 [15] has been deposited as strain HM-818 to the BEI resources (beiresources.org) and has been sequenced. It is equivalent to $R$. aeria Oral Taxon 188, strain F0474 (HMP ID 1324). R. aeria bacteria were grown on Brucella agar plates (Hardy Diagnostics, Santa Maria, CA, USA) at $37^{\circ} \mathrm{C}$ for $48 \mathrm{~h}$ under aerobic conditions. The cells were harvested from the plate with a cotton swab and suspended in sterile PBS to an OD620 180. Aliquots of $1.5 \mathrm{~mL}$ of the suspension were centrifuged and the supernatants were removed. The cell aliquots comprising approximately $1.59 \times 10^{7}$ cells/mL were lyophilized in a SpeedVac and stored at $-80^{\circ} \mathrm{C}$.

Preparation of mouse chow admixed with Rothia bacteria-Mouse chow (2018, Envigo, Cambridgeshire, UK) with bacteria was prepared in advance of the in vivo experiment. The chow used contains approximately $18 \%$ crude protein. An aliquot of $1 \mathrm{~g}$ of mouse chow, containing $50 \%$ wheat as protein source, containing roughly $10 \%$ of gluten and $8 \%$ gliadin, approximately $25 \mathrm{mg}$ of gliadin was dry mixed with lyophilized R. aeria bacteria at a ratio of $1.6 \times 10^{7}$ cells/gram chow. The mixture of Rothia bacteria and chow were added to a $2 \mathrm{~mL}$ Eppendorf tube and water was added incrementally in less than $1 \mathrm{~min}$ to form a slurry. The chow slurry was dried in the SpeedVac (SpeedVac plus SC110 A, Savant, NY, USA) for $3 \mathrm{~h}$ during which the slurry was frozen. The resultant pellet was removed from the Eppendorf tube and was visually similar to an original chow pellet. 
In vivo digestion by Rothia bacteria-Nine-week-old female Balb/c mice ( $\mathrm{n}=9$ mice/group) were fasted for $24 \mathrm{~h}$ and then fed $1 \mathrm{~g}$ of mouse chow with and without added R. aeria bacteria. Mice in both groups ingested the chow within $1 \mathrm{~h}$ and then were allowed to digest the chow for an additional $2 \mathrm{~h}$. Stomach and (proximal) small intestine were harvested. Stomach and small intestinal contents were collected and centrifuged $(2000 \times g, \times 10 \mathrm{~min}$, Thermo Scientific legend X1R, USA). The supernatants were collected and boiled $\left(100{ }^{\circ} \mathrm{C}, 10 \mathrm{~min}\right)$, then mixed with $60 \%$ ethanol to extract the gliadins by shaking $(40 \mathrm{rpm})$ at room temperature for $1 \mathrm{~h}$ and centrifuged $\left(2000 \times g \times 10 \mathrm{~min}, 4^{\circ} \mathrm{C}\right)$. The supernatants were collected, and protein concentrations determined with the BCA protein assay.

Gliadin degradation-Since approximately one third of the food protein were found in the small intestine and two thirds in the stomach, and only negligible amounts of gliadin in chow were found in the small intestine (with less than $10 \%$ of the gliadin that were detectable in the stomach), gliadin degradation was only assessed in the harvested stomach samples by SDS PAGE and immunoblotting using a rabbit polyclonal anti-gliadin-peroxidase conjugated antibody produced (Sigma A1052-1ML). Densitometric analysis of the obtained signals was carried out by drawing equal size boxes around the bands in the gel of $37 \mathrm{kDa}$ and $50 \mathrm{kDa}$ bands, representing the $\alpha / \beta$ and $\gamma$ gliadins, respectively. The data were corrected for intensity level after subtracting the background by selecting a blank area in the image on the different gels. The data from the various gels were normalized to $5 \mu \mathrm{g}$ of gliadin (provider) loaded on each gel. Analyses of band intensities were carried out using Quantity one software.

Gliadin epitope neutralization-Hydrolysis of gliadin immunogenic epitopes in the harvested stomach contents was assessed with the R5 ELISA assay (RIDASCREEN Gliadin-R-Biopharm AG \#R7001, Darmstadt, Germany) that measures an immune dominant omega-gliadin epitope. The protein concentration of the stomach samples was adjusted to $160 \mu \mathrm{g} / \mathrm{mL}$, and diluted 3200-fold in dilution buffer, securing linearity in relation to the standard curve. Aliquots of $100 \mu \mathrm{L}$ of each of the diluted samples, as well as the controls of the $0 \mathrm{ppb}$ and $80 \mathrm{ppb}$ gliadin standard solutions included in the kit, were added to each well. The assay was conducted according to the manufacturer's instructions.

\subsection{In Vitro Gliadin Digestion by Live and Dead Rothia Bacteria}

R. aeria and R. mucilagiosa cell killing-The two oral isolates, R. mucilaginosa ATCC 25296 and R. aeria (strain WSA-8) were cultured on Brucella agar plates, harvested and diluted in triplicate to an OD620 of 1.2 in either $1 \mathrm{~mL}$ of $70 \%$ ethanol or in $1 \mathrm{~mL}$ of saliva ion buffer (SIB), containing $50 \mathrm{mM}$ $\mathrm{KCl}, 1.5 \mathrm{mM}$ potassium phosphate, $1 \mathrm{mM} \mathrm{CaCl}_{2}$ and $0.1 \mathrm{mM} \mathrm{MgCl}_{2}, \mathrm{pH}$ 7.0. The bacterial cell suspensions were incubated for $30 \mathrm{~min}$ at $37^{\circ} \mathrm{C}$ and $5 \mu \mathrm{L}$ aliquots were plated in triplicate on Brucella agar. The residual $995 \mu \mathrm{L}$ aliquots were lyophilized to dryness using a SpeedVac (Thermo Fisher, Waltham, MA, USA). The lyophilized bacteria in $70 \%$ ethanol were reconstituted in $1 \mathrm{~mL}$ sterile SIB, and the lyophilized bacteria in SIB were reconstituted in deionized sterile water, to obtain the same final ion composition in both samples. The reconstituted cell samples were used to determine gliadin degrading enzyme activity.

In gel gliadin degradation-Zymogram gels $(6 \%)$ were prepared using gliadin from wheat (Sigma, St. Louis, MO, USA) as the gel-incorporated substrate, as previously described [16]. In brief, bacteria from the above reconstituted suspensions equivalent to $600 \mu \mathrm{l}$, were harvested, suspended in $30 \mu \mathrm{L}$ zymogram sample buffer, and loaded onto a zymogram gel. Electrophoresis was carried out at $100 \mathrm{~V}$ at $4{ }^{\circ} \mathrm{C}$, and gels were renatured and developed in zymogram renaturing and developing buffers (InVitrogen, Carlsbad, CA, USA) according to the manufacturer's instructions. After $48 \mathrm{~h}$ of development at $37^{\circ} \mathrm{C}$, gels were stained with $0.1 \%$ Coomassie Brilliant Blue as described [16].

Synthetic tripeptide substrates hydrolysis-In a 96 well microtiter plate aliquots of $200 \mu \mathrm{L}$ aliquots of the reconstituted Rothia aeria and R. mucilaginosa cell suspensions were mixed with $20 \mathrm{mM}$ Z-Tyr-Pro-Gln-pNA (Z-YPQ-pNA) (21st Century Biochemicals, Marlborough, MA, USA). The final substrate concentration was $200 \mu \mathrm{M}$. All experiments were performed in triplicate. Substrate hydrolysis was monitored spectrophotometrically at $405 \mathrm{~nm}$, using a Genios microtiterplate reader (Tecan Group 
Ltd., Männedorf, Switzerland) and Deltasoft software, with the equipment temperature set at $37^{\circ} \mathrm{C}$. Readings were performed in the kinetic mode at selected time intervals to capture the linear part of the conversion curve.

\subsection{Isolation and Identification of the Gluten-Degrading Enzyme from R. aeria}

To identify the gluten-degrading enzyme produced by R. aeria, the bacteria were cultured on Brucella agar plates (Hardy Diagnostics, Santa Maria, CA, USA) at $37{ }^{\circ} \mathrm{C}$ for $48 \mathrm{~h}$ under aerobic conditions. The cells were harvested from the plate with a cotton swab and suspended in sterile PBS to an OD620 5.0. Four aliquots of $1.5 \mathrm{~mL}$ of the suspension were centrifuged $\left(2000 \times g, 10 \mathrm{~min}, 4{ }^{\circ} \mathrm{C}\right)$ and the supernatants were removed.

SDS-PAGE and casein zymography-The four cell pellets were re-suspended each in $200 \mu \mathrm{L}$ zymogram sample buffer [13], and subject to a non-reducing (no DTT or $\beta$-mercaptoethanol-containing) $6 \%$ SDS-PAGE gel of $16 \times 20 \times 0.15 \mathrm{~cm}$, using a protean II xi cell system (Bio-Rad, Hercules, CA, USA). The composition of this gel was the same as that of previously published $6 \%$ gliadin zymogram gels but without incorporation of gliadin [13]. After electrophoresis at a constant voltage of $120 \mathrm{~V}$ at $4{ }^{\circ} \mathrm{C}$, the gel was divided in two halves. The first half was stained with $0.1 \%$ Coomassie Brilliant Blue in $40 \%(v / v)$ methanol/10\% $(v / v)$ acetic acid. The second half was developed as a zymogram gel to reveal enzyme activity associated with the bands [14]. To this effect, the zymogram gel half was washed twice for $30 \mathrm{~min}$ in buffer containing 2.5\% Triton X-100 (renaturing buffer; Life Technologies, Carlsbad, CA, USA), followed by washing twice for $1 \mathrm{~h}$ in buffer containing $20 \mathrm{mM}$ Tris- $\mathrm{HCl}, \mathrm{pH} 7.5$ (developing buffer; Life Technologies, Carlsbad, CA, USA). Gel A was then incubated in developing buffer supplemented with $1 \%$ casein (Sigma, St. Louis, MO, USA) at $37^{\circ} \mathrm{C}$ for $1.5 \mathrm{~h}$, followed by a washing step for $2 \mathrm{~min}$ and staining with $0.1 \%(w / v)$ Coomassie Brilliant Blue in $40 \%(v / v)$ methanol/10\% $(v / v)$ acetic acid for $24 \mathrm{~h}$. Both gel halves were then de-stained in 40\% $(v / v)$ methanol/10\% (v/v) acetic acid until optimal contrast was achieved.

LC-ESI-MS/MS-The gel halves described above were aligned, and the proteins displaying enzyme activity were excised. The proteins were digested in-gel with sequencing-grade trypsin, and the peptides were eluted and separated by in-line C18 chromatography, as previously described [14]. In brief, the amino acid sequences of the peptide ions were obtained with an LTQ Orbi-trap mass spectrometer (ThermoFinnigan, San Jose, CA, USA). The b- and y-ion spectra were searched against a database of R. aeria F0474, supplemented with decoy proteins as well as the three Rothia subtilisin genes published previously [14]. The filter settings selected were $X$-corr values $>2.2$ and 3.5 for $Z=2$, and 3, respectively. The deltaCn and peptide probability settings were $>0.1$ and $<0.01$, resp.

Statistical analysis-The in vivo digestion data were analyzed using SPSS 17.0 software and computed with GraphPad Prism 8. The non-parametric Mann-Whitney test was used to test for statistical significance between groups. The data are represented as the average \pm standard error of the mean (SEM), and a value of $p<0.05$ was considered to be statistically significant.

\section{Results}

\subsection{In Vivo Digestion by life Rothia Bacteria}

Mice were fed chow with and without $R$. aeria bacteria, and digestion of the gluten was monitored in samples removed from the digestive tract. During preparation of the chow/R. aeria mixture, gliadin remained intact (Supplemental Figure S1, lanes 2 and 5). In mice fed the chow/R. aeria mixture, after $2 \mathrm{~h}$ of digestion, most of the chyme was present in the stomach, as evidenced by total protein determination (Figure 1A), SDS page (Figure 1B; left panel) and anti-gliadin immunoblotting (Figure 1B, right panel) of samples harvested from the stomach, duodenum, jejunum, and ileum. 
A

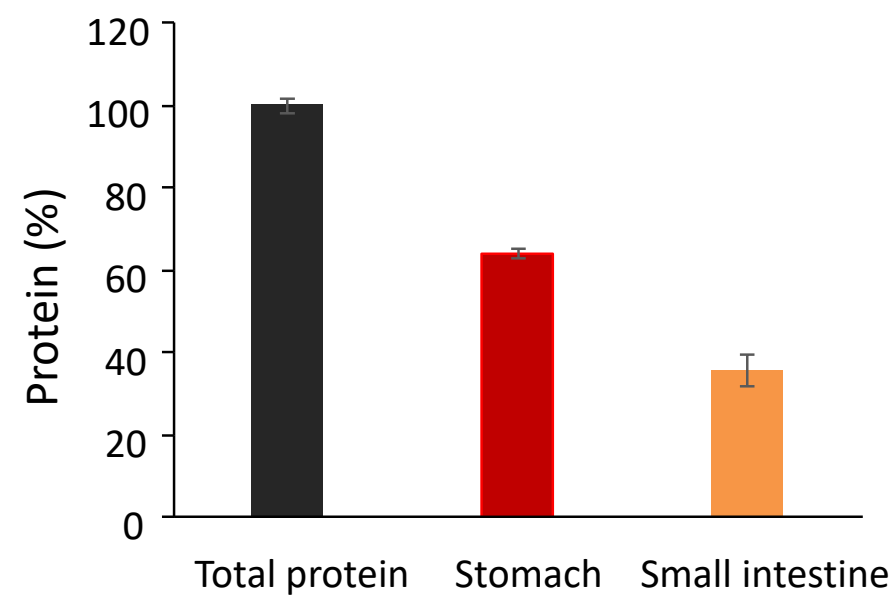

B
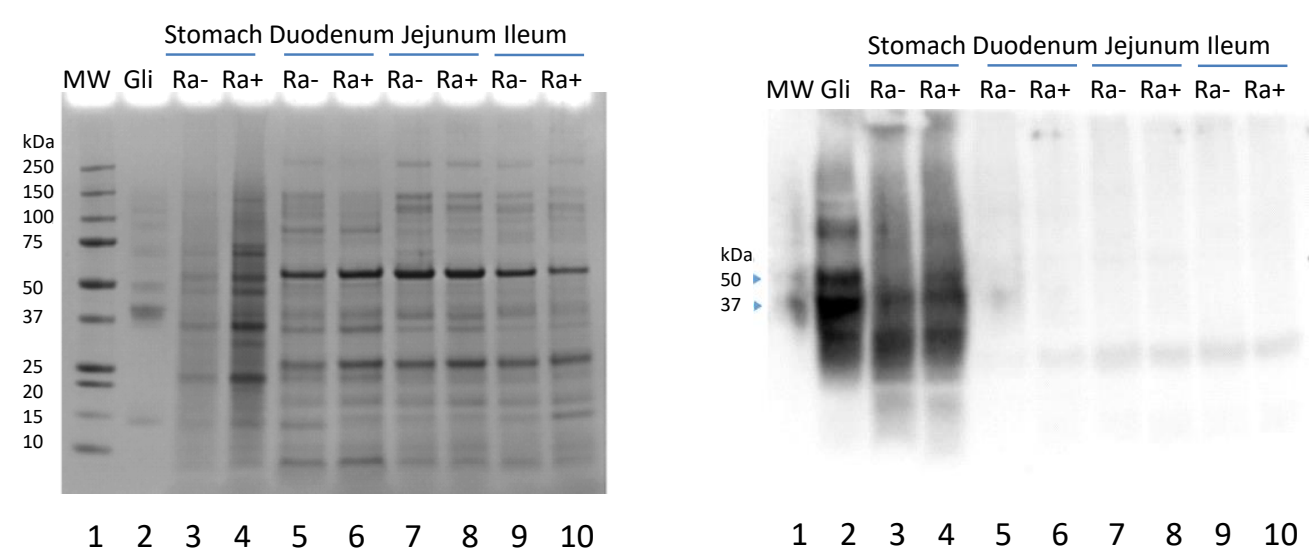

Figure 1. Analysis of gastric and small intestinal contents. (A) Total protein content of the contents in the stomach (red) and small intestine (orange); $\mathrm{n}=4$ per organ; protein was determined by the BCA method multiplied by sample volume and divided by the total protein in both the stomach and intestine. (B) Analysis of gliadin in gastro-intestinal samples by SDS-PAGE (left panel) and anti-gliadin immunoblotting (right panel). Aliquots (63 $\mu$ g protein) of the gastro-intestinal samples with $R$. aeria $(\mathrm{Ra}+)$ and without $R$. aeria $(\mathrm{Ra}-)$ bacteria were loaded on two 4-12\% SDS-PAGE gels. After electrophoresis the gels were either stained with Coomassie brilliant blue (left) or processed by immunoblotting with an anti-gliadin antibody (right). Lanes 1: Protein standard, $5 \mu \mathrm{L} ; 2$ : Gliadin control (Gli, $25 \mu \mathrm{g})$; 3: stomach Ra (-);4: stomach Ra (+);5: duodenum Ra (-);6: duodenum $\operatorname{Ra}(+)$; 7: Jejunum Ra (-);8: jejunum Ra (+); 9: ileum Ra (-); 10: ileum Ra (+). Arrows: gliadin bands at 37 and $50 \mathrm{kDa}$.

The in vivo digestion experiments were carried out with 9 female mice per group. After an overnight fast, the control and experimental groups were fed chow without and with $R$. aeria for $1 \mathrm{~h}$, respectively, and euthanized $2 \mathrm{~h}$ thereafter. All mice ingested the chow within $1 \mathrm{~h}$, and therefore, the effective digestion time was $2 \mathrm{~h}$. Gliadin levels in the stomach samples from mice fed with and without $R$. aeria were determined from the densitometric analysis of the major gliadin bands at 37 and $50 \mathrm{kDa}$ in sample aliquots normalized to for total protein content (Figure 2A). The gliadin amount significantly decreased in the $\mathrm{Ra}(+)$ group compared to $\mathrm{Ra}(-)$ group (Figure $2 \mathrm{~B})$.

To investigate the survival of immunogenic epitopes in the harvested stomach samples, an ELISA test was carried out using R5 monoclonal antibody, specifically recognizing the QQPFP, QQQFP, and LQPFP immunogenic epitopes $[13,17]$. The average values for the mice fed with chow supplemented with $R$. aeria was $16.8 \pm 0.15 \mathrm{ppm}$ (OD 0.63) compared to $25.1 \pm 0.23 \mathrm{ppm}$ (OD 0.88) for the control group. This reduction of the gliadin immunogenic epitopes as detected by ELISA is therefore in accord 
with the western blot results, showing a statistically significant reduction of $32.6 \%$ as compared to the control mice (Figure 2C).

A

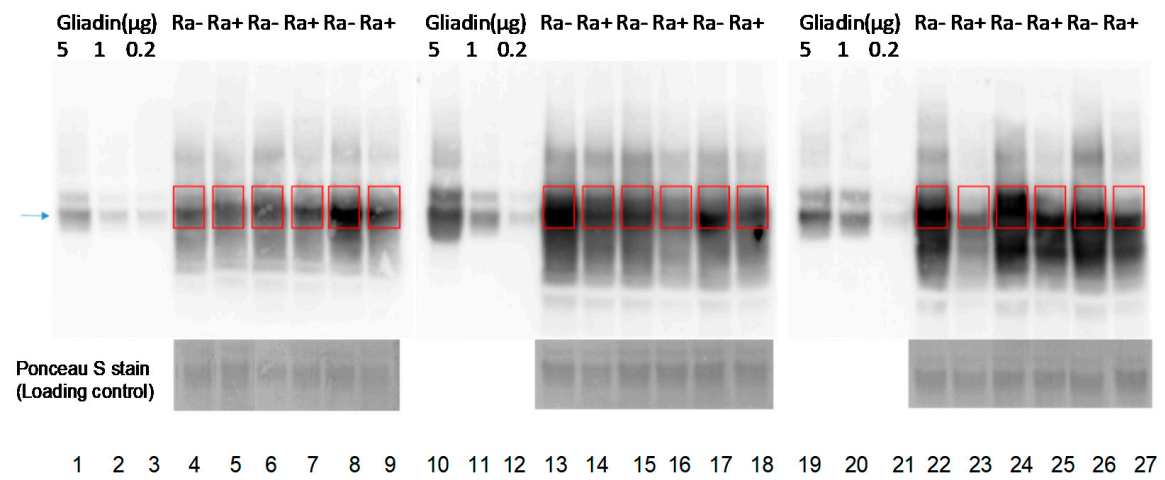

B

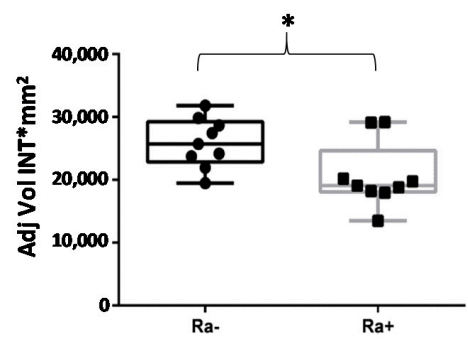

C

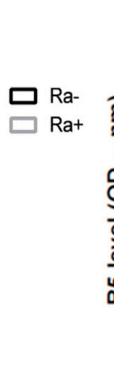

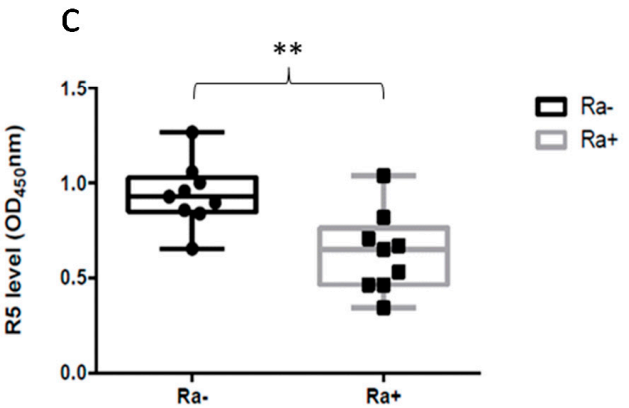

Figure 2. Gliadin degradation in vivo by Rothia bacteria. (A) Two groups of mice (M) were fed chow without R. aeria and chow with R. aeria. Aliquots (160 $\mu \mathrm{g}$ protein) of the gastric samples with (Ra+) and without ( $\mathrm{Ra}-$ ) bacteria ( $\mathrm{n}=9$ /group) were subjected to immunoblotting with an anti-gliadin antibody. Lane 1, 2, 3; 10, 11, 12; 19, 20, 21: Gliadin control (5, 1 and $0.2 \mu \mathrm{g})$, respectively; Lanes 4, 6, 8, 13, 15, 17, 22, 24, 26: the nine mice fed chow without $R$. aeria bacteria $R a(-)$; Lanes 5, 7, 9, 14, 16, 18, 23, 25, 27 : the nine mice fed chow with $R$. aeria bacteria $\mathrm{Ra}(+)$. The blue (arrow) pointed to the gliadin bands at $37 \mathrm{kDa}$. (B) Densitometric analysis of the major gliadin protein bands (shown in A); data points represent the average of the remaining gliadin amount (AU). The data represent three independent experiments and the error bars \pm SEM. ${ }^{*} p<0.05$. (C), R5 epitope levels, expressed in OD450nm, in stomach samples from mice fed chow supplemented with R. aeria $(\mathrm{Ra}+)$ and without $R$. aeria $(\mathrm{Ra}-)$. The data are representative of three independent experiments and the error bars represent the average \pm SEM. ${ }^{* *} p<0.01$.

\subsection{In Vitro Gluten Digestion by Dead Rothia Bacteria}

In view of the concern that some probiotics, even if they represent harmless colonizers, might favor opportunistic infections in immunocompromised hosts, we investigated if the cell-associated enzyme activities were maintained after abolishing the viability of Rothia bacteria. To achieve cell killing with an agent that can be removed after treatment, R. mucilaginosa ATCC 25296 and R. aeria (WSA-8) bacteria were incubated in $70 \%$ ethanol or in saliva ion buffer (SIB, control). After 30 min of incubation, cell viabilities were determined by plating aliquots of the ethanol or SIB-treated cells in triplicate on agar (Figure 3A). Enzyme activities in the ethanol or SIB-incubated cell suspensions were evaluated qualitatively by zymography (Figure 3B), and quantitatively with the tripeptide substrate Z-YPQ-pNA (Figure 3C). The maximum rates of Z-YPQ-pNA hydrolysis are depicted in Figure 3D. Results showed complete loss of cell viability for both strains after incubation with 70\% ethanol, but not with SIB (Figure 3A). Remarkably, enzyme activities were maintained, as evidenced from clear bands in the zymogram of the ethanol treated and untreated samples (Figure 3B). The tripeptide hydrolysis rates depicted in Figure 3C,D, show that on average less than $10 \%$ of the enzyme activity was lost following 
$70 \%$ ethanol treatment. Overall, the method was an effective, food security compatible approach to abolish bacterial viability without impairing the desired gluten-degrading enzyme activities.

A

\section{$\begin{array}{lll}\text { R. mucilaginosa ATCC } 25296 & R \text {. aeria WSA-8 }\end{array}$}
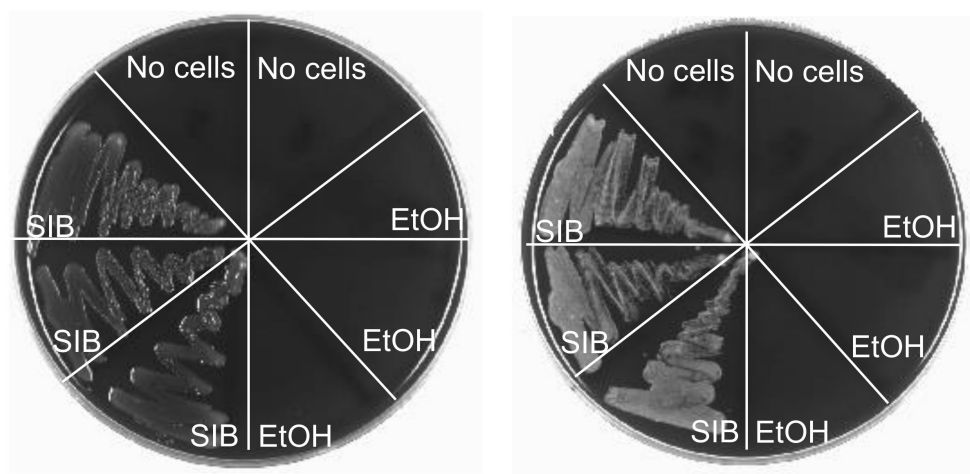

B
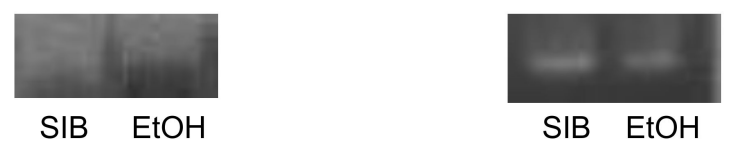

C
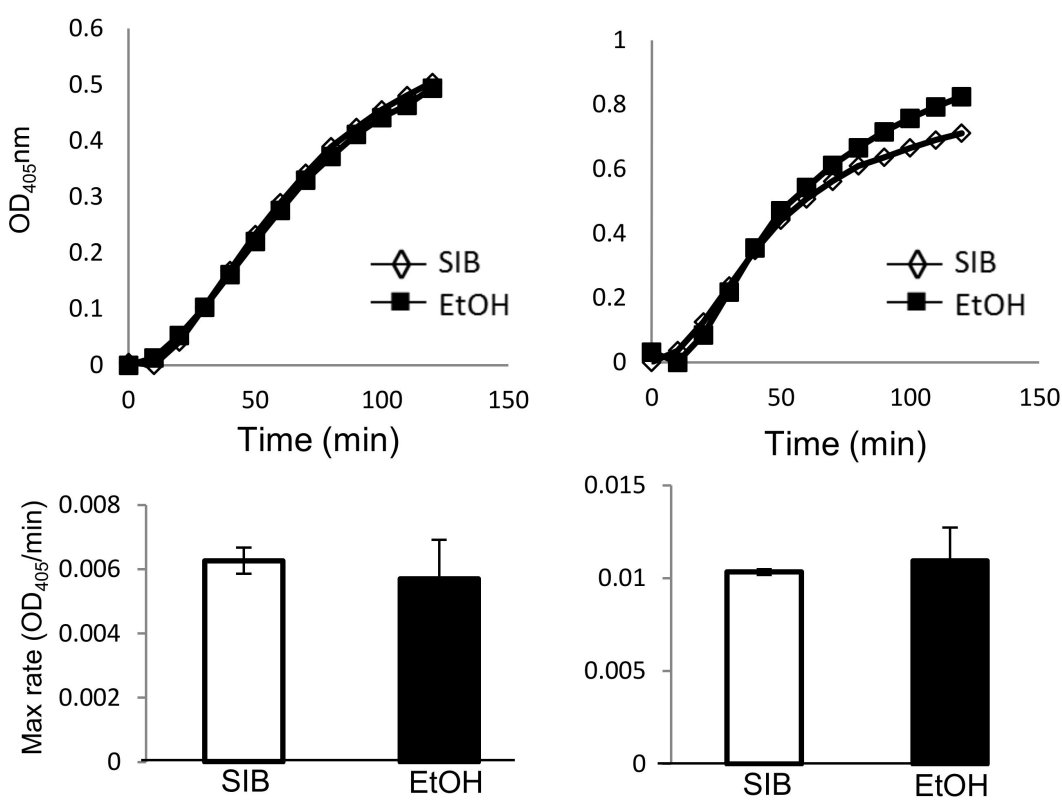

Figure 3. Gliadin epitope degradation by R. mucilaginosa and R. aeria bacteria incubated in SIB or ethanol. The bacterial cells were suspended in salivary ion buffer (SIB, pH 7.0) or 70\% ethanol (EtOH) to a final suspension cell density at $\mathrm{OD}_{620}$ of 1.2, and incubated at room temperature for $30 \mathrm{~min}$. After lyophilization and reconstitution, cell viability, and enzyme activities were determined. (A) Cell viability assessed by plating $5 \mu \mathrm{L}$ aliquots in triplicate on BA. (B) Cell associated enzyme activities determined by gliadin zymography (zoom of enzyme active band only). (C) hydrolysis plots of Z-YPQ pNA (Rothia strains). (D) Average maximum substrate hydrolysis rates derived from data in (C). Left, R. mucilaginosa ATCC 25296; right, R. aeria WSA-8.

\subsection{Isolation and Identification of the Gluten-Degrading Enzyme from R. aeria}

To identify the gluten-degrading enzyme from R. aeria, a large SDS gel $(16 \times 20 \mathrm{~cm})$ was used for optimal protein separation. A low percentage gel (6\%) facilitated separation of proteins with molecular weights $>50 \mathrm{kDa}$. From our previous study it was known that the $R$. aeria enzyme migrated 
at approximately $75 \mathrm{kDa}$ [15]. As an externally added substrate, casein instead of gliadin was added. Casein has a better solubility than gliadin and can be used as alternative substrate to reveal the gliadin-degrading enzymes in zymogram gels, giving a better contrast than gliadin $[14,18]$.

The zymogram provided evidence for a single band migrating at $\sim 75 \mathrm{kDa}$ with enzyme activity, and the matching non-denaturing Coomassie-stained gel showed a major band migrating at the same position (Figure $4 \mathrm{~A}, \mathrm{~B})$. As a control, proteins were also analyzed on a denaturing gel, showing the full spectrum of proteins migrating into the gel under these conditions (Figure $4 \mathrm{C}$ ). The bands labeled 1-4 in Figure 4A,B were excised and subjected to mass spectrometric analysis. They were searched against a $R$. aeria database, comprising protein entries derived from the whole genome of $R$. aeria as well as protein entries from $R$. mucilaginosa and $R$. dentocariosa subtilisin genes.

As expected, more than one protein was identified in each band. In total 3, 4, 23, and 23 proteins were identified by $>2$ unique peptides in bands $1,2,3$, and 4 , respectively. The most prominent protein in all four samples, identified with high confidence, was peptidase S8, KGJ00122.1. It was represented by $32,30,33$, and 41 unique peptides, in the four excised bands, resp. A blast search of KGJ00122.1 revealed that it is $99 \%$ homologous to a $R$. aeria protein annotated as glycerol-3P-ABC transporter in NCBI (BAV86562.1). Sequence analysis of BAV86562.1 revealed that it is a subtilisin family member, because it contains the cd07474 domain that is characteristic of the peptidase S8 family domain. The sequence and the $\mathrm{D}, \mathrm{S}$, and $\mathrm{H}$ amino acids of the catalytic triad present in this peptidase domain are shown in Supplementary Figure S3.

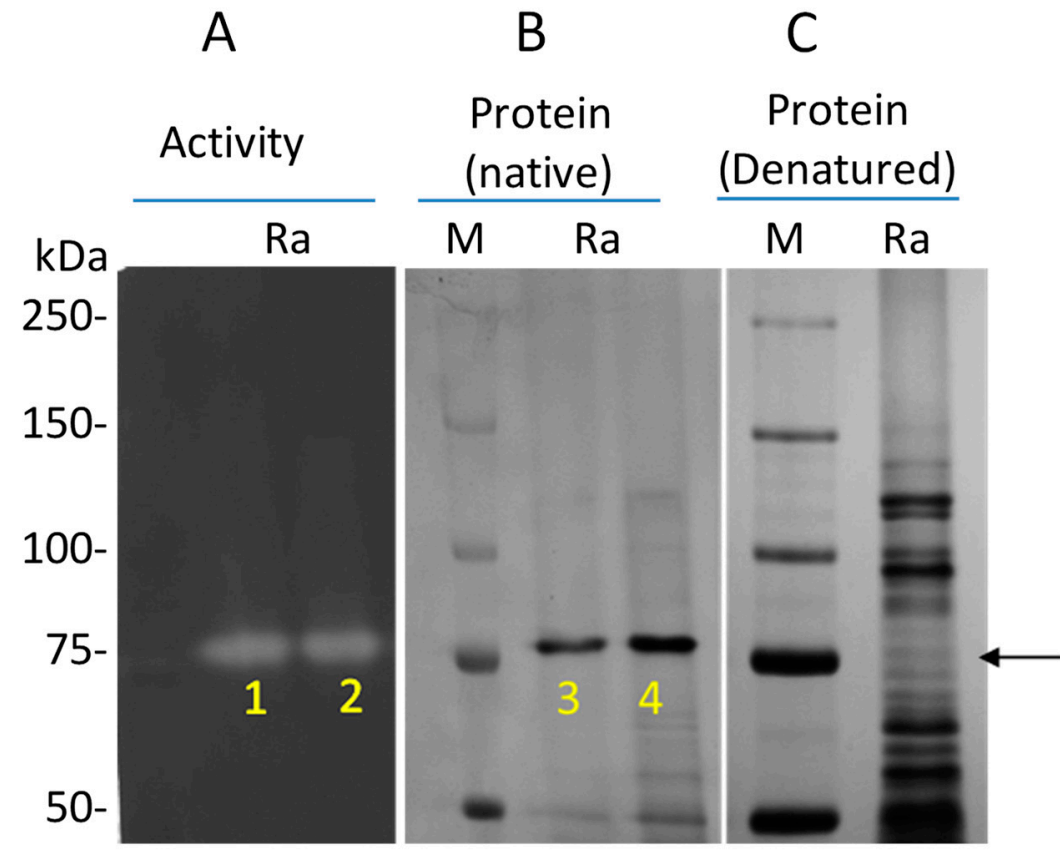

Figure 4. Identification of the gluten degrading enzyme from $R$. aeria. (A) Gel part developed as a zymogram gel using externally added casein as the enzyme substrate to visualize bands with enzyme activity (indicated with an arrow). (B) Native PAGE gel part stained with Coomassie brilliant blue. (C) SDS-PAGE mini gel stained with Coomassie brilliant blue. Bands 1-4 were excised and subjected to mass spectrometric analysis.

\section{Discussions}

While oral bacteria are present in high amounts and in a wide variety in the oral cavity, being swallowed in large numbers daily, their roles beyond the oral cavity are not well understood. In the first part of the present work, we demonstrated that Rothia species can degrade dietary proteins, specifically gluten, in vitro, as well as in vivo. This suggests that this species, and perhaps some other 
oral microbes as well, may play a role in the initiation of the digestion of these protein components of foods.

There is a great interest among $\mathrm{CeD}$ patients in a medical therapy that can ameliorate gluten-induced adverse effects that can also occur with trace amounts that celiacs may ingest with a supposed gluten free diet (GFD). A pharmacological therapy should eliminate the effect of milligram quantities up to a few grams of gluten in a largely GFD that avoids overt gluten sources, such as bread, pizza, pasta, or cookies. Most CeD patients agree that such a diet would be much more sustainable, since the required strictly gluten free diet (less than 20 ppm of gluten in all foods, i.e., less than $20 \mathrm{mg} / \mathrm{kg}$ ) is a great challenge in everyday life [19]. Thus, in a double blind clinical study, CeD patients in remission who were challenged with $50 \mathrm{mg}$ gluten daily developed an average $20 \%$ decrease in villous height/crypt depth vs. placebo within 90 days [20], indicating that such minor amounts of gluten can cause chronic mucosal damage. In addition, a high sensitivity to minor amounts of gluten may underly refractory celiac disease type 1.

A major therapeutic approach to such supportive therapy is the use of bacterial of grain-derived gluten-degrading enzymes, first spearheaded by the group of Khosla [4,21-26] while commercially available "glutenases" have no or little proven efficacy to effectively degrade antigenic gluten peptides [26,27]. R. aeria is a gram-positive bacterium belonging to the Rothia genus and a natural colonizer of the oral cavity, similar to $R$. mucilaginosa and $R$. dentocariosa. R. aeria exhibits a superior gliadin degrading activity compared to $R$. mucilaginosa [15]. The finding suggests that Rothia species, in particular $R$. aeria, as nonpathogenic human colonizers, may be considered as promising new candidates for enzyme therapeutics in CeD.

Gliadin degradation is dependent on the amount of bacteria, the amount of gluten protein, the food matrix, $\mathrm{pH}$, and incubation time. With regard to the bacterial count, we found that $R$. aeria exerted gliadin degradation in a dose dependent manner. Based on in vitro studies employing various ratios of bacteria and gliadin, a dose of $1.6 \times 10^{7} \mathrm{CFU} / \mathrm{g}$ of chow was selected for the in vivo study. This dose is not unrealistic, considering that probiotic applications can contain as high as $10^{11}$ up to $10^{12} \mathrm{CFU}$ per application [28]. Given the body weight of mouse of about $20 \mathrm{~g}$, the dose calculated for a $70 \mathrm{~kg}$ human would be $\left(1.6 \times 10^{7} \times 20 \times 3500=\sim 10^{12}\right)$. The time between the end of the $1 \mathrm{~h}$ chow feed and sacrifice of the mice was $2 \mathrm{~h}$. The selected time span was based on a report that assessed the gastrointestinal transit time in mice with 99mTc-DTPA-labeled activated charcoal. Within 2-3 h the labelled material was detected in the stomach and the entire small intestine [29]. Therefore, $2 \mathrm{~h}$ digestion including a $1 \mathrm{~h}$ complete ingestion of the food pellet was selected for the in vivo experiments.

Effective gastric digestion is essential before immunogenic gluten peptides reach the proximal small intestine where they can elicit celiac disease. Therefore, we focused on gastric gliadin digestion. The in vivo experiment with nine mice per group showed that $R$. aeria bacteria significantly reduced the amount of intact gliadin molecules in the stomach before they reached the duodenum. Importantly, this reduction was paralleled by a significant disappearance of major immunogenic gliadin epitopes as assessed with the R5 gliadin ELISA. Rizzello et al. have demonstrated the efficiency of wheat dough fermentation with Lactobacilli and fungal proteases using a similar approach in vitro [30].

Gluten-degrading microbes, especially if they are natural colonizers of the human body, are of high interest for exploitation as treatments of $\mathrm{CeD}$, since they carry the potential to be explored in the form of probiotics [26]. Highly effective prolyl- and glutamine-endopeptidases for degradation of immunogenic gluten epitopes are produced by various microorganisms. However, some of the discovered gluten-degrading microbes are opportunistic pathogens and/or demonstrate associations with human diseases. Thus, several gluten-degrading natural colonizers of the human body are not necessarily harmless. Examples are Capnocytophaga sputigena, Neisseria mucosa, or Pseudomonas species, which rapidly cleave immunogenic gluten domains, yet have been implicated in periodontal [31-33] and endodontic infections [34], or more general organ pathology [35]. The oral cavity and the gut are usually colonized with balanced quantities of such opportunistic pathogens. The opportunistic/pathogenic 
features limit or eliminate their potential utilization as probiotic agents; but do not exclude the use of the purified enzymes.

In this vein, safety is a major concern when live bacteria are considered as probiotic for CeD. The search for an effective and non-toxic probiotic for the treatment of $\mathrm{CeD}$ has become a topic of high importance for the celiac community and health care providers $[4,22,26,36]$. Food-grade proteases capable of detoxifying moderate quantities of dietary gluten could help mitigate this problem [24,26]. In search for alternatives, natural human gluten-degrading microbial colonizers, in a live form when harmless, or neutralized with ethanol treatment, could potentially offer the basis for the development of new and low-cost therapeutics for $\mathrm{CeD}$. In the present study, we developed a method to abolish toxicity associated with the live cells without affecting gluten-degrading activities. The bacterial treatment with $70 \%$ ethanol killed the live bacteria, retained gliadin degrading activity, and the added ethanol can be fully removed by lyophilization. While ethanol treatment will not neutralize cell-associated lipopolysaccharide, or certain exotoxins or endotoxins, it abolishes cell viability, colonization capacity, and potential of active transfer of virulence factors and antibiotic resistance genes to other bacteria. Our study also shows that a range of antibiotics (Supplemental Figure S2) effectively abolished the viability of four gluten-degrading microbial strains. Thus, there are several strategies to safely apply Rothia bacteria, e.g., in an ethanol-killed formulation, to patients with $\mathrm{CeD}$, and/or to treat Rothia infections effectively with antibiotics, should any infection occur.

We previously identified the gliadin-degrading enzyme from $R$. mucilaginosa [15]. In the present study, we identified the R. aeria enzyme a subtilisin-like serine protease belonging to the S8 peptidase family. These subtilisins can rapidly hydrolyze gliadin immunogenic epitopes, efficiently degrade the immunogenic gliadin-derived 33-mer peptide, and can be considered promising new candidates for enzyme therapeutics in $\mathrm{CeD}$ [26]. The R. aeria protein identified in the gliadin degrading protein band matched with BAV86562.1. This protein was seemingly incorrectly annotated as a glycerol-3-phosphate-ABC transporter in the NCBI data base, since it lacks the structural features of an $A B C$ transporter. $A B C$ transporters are characterized by two transmembrane domains and two nucleotide-binding domains, containing the signature sequence LSGGQ, which is directly involved in nucleotide binding [37]. BAV86562.1 does not contain these domains and the LSGGQ sequence. In contrast, it does contain the D-H-S (Asp-His-Ser) catalytic amino acid triad with flanking regions characteristic for the subtilisin family of proteases. Thus, BAV86562.1 expressed by R. aeria is a S8 subtilisin peptidase and not an $\mathrm{ABC}$ transporter.

Peptidase $\mathrm{S} 8$ belongs to the subtilases superfamily, a group of enzymes which were first isolated from Bacillus subtilis, a species inhabiting, e.g., soils [38]. Since Bacillus species are also present in the oral cavity, like Rothia species [8], we compared the R. aeria and B. subtilis gliadin-degrading activities. R. aeria was found to have a higher activity than B. subtilis. More importantly, R. aeria, but not B. subtilis, exerted appreciable activity at an acidic $\mathrm{pH}$, i.e., gastric $\mathrm{pH} 3.0$, that is found $1 \mathrm{~h}$ after food ingestion [39]. This clearly qualifies the R. aeria subtilisin that we identified in this study to serve as an enzyme source that can degrade immunogenic gluten epitopes in the stomach, before they reach the duodenum to elicit intestinal inflammation in patients with $\mathrm{CeD}$. Since the $R$. aeria enzyme can be cloned and expressed in high doses, and since it may be suitable for further optimization towards even higher gluten degrading efficacy in the stomach, clinical applications should be explored.

Supplementary Materials: The following are available online at http://www.mdpi.com/2072-6643/12/12/3724/s1. Supplemental Figure S1. Enzymatic degradation of gliadins in mouse chow in vitro detected by immunoblotting; Supplemental Figure S2. MIC Susceptibility of two Rothia species to antimicrobics; Supplemental Figure S3. Amino acid sequence of $R$. aeria BAV86562.1.

Author Contributions: Conceptualization, G.W., D.S., and E.J.H.; Data curation, G.W., G.D., D.S., and E.J.H.; Formal analysis, G.W., D.S., and E.J.H.; Funding acquisition, D.S. and E.J.H.; Investigation, G.W., G.D., D.S., and E.J.H.; Methodology, G.W., G.S., and E.J.H.; Project administration, G.W., D.S., and E.J.H.; Supervision, F.G.O., D.S., and E.J.H.; Writing-original draft, G.W., D.S., and E.J.H.; Writing—review and editing, F.G.O., D.S., and E.J.H. All authors have read and agreed to the published version of the manuscript. 
Funding: D.S. has received project-related support by research grants from the German Research Foundation DFG Schu 646/17-1 (Wheat and ATI), DFG Schu 646/20-1 (Allergy), DFG Pic/Schu SPP1656 (Intestinal microbiota), DFG TR128 project A08 (Collaborative Research Center on Multiple Sclerosis), and by a research grant from the Leibniz Foundation SAW-2016-DFA-2 (Wheatscan). E.J.H. was supported by the National Institutes of Health and the National Institute of Allergy and Infectious Diseases grants R01 AI087803, K02 AI101067, and by a Boston University Ignition Award and a Boston University CTSI Award.

Acknowledgments: We thanks Ross Tomaino, Harvard Medical School, Taplin Mass Spectrometry Facility for LC-ESI-MS/MS analysis. We would also like to thank David Cawston, MHA, RLATG, Boston University Animal Science Center for animal handling training.

Conflicts of Interest: The authors declare no conflict of interest.

\section{References}

1. Schuppan, D.; Junker, Y.; Barisani, D. Celiac disease: From pathogenesis to novel therapies. Gastroenterology 2009, 137, 1912-1933. [CrossRef]

2. Fasano, A.; Catassi, C. Clinical practice. Celiac disease. N. Engl. J. Med. 2012, 367, 2419-2426. [CrossRef] [PubMed]

3. Helmerhorst, E.J.; Zamakhchari, M.; Schuppan, D.; Oppenheim, F.G. Discovery of a novel and rich source of gluten-degrading microbial enzymes in the oral cavity. PLoS ONE 2010, 5, e13264. [CrossRef]

4. Gass, J.; Khosla, C. Prolyl endopeptidases. Cell Mol. Life Sci 2007, 64, 345-355. [CrossRef] [PubMed]

5. Hausch, F.; Shan, L.; Santiago, N.A.; Gray, G.M.; Khosla, C. Intestinal digestive resistance of immunodominant gliadin peptides. Am. J. Physiol. Gastrointest. Liver Physiol. 2002, 283, G996-G1003. [CrossRef] [PubMed]

6. Mitea, C.; Havenaar, R.; Drijfhout, J.W.; Edens, L.; Dekking, L.; Koning, F. Efficient degradation of gluten by a prolyl endoprotease in a gastrointestinal model: Implications for coeliac disease. Gut 2008, 57, 25-32. [CrossRef]

7. Vader, L.W.; Stepniak, D.T.; Bunnik, E.M.; Kooy, Y.M.; de Haan, W.; Drijfhout, J.W.; Van Veelen, P.A.; Koning, F. Characterization of cereal toxicity for celiac disease patients based on protein homology in grains. Gastroenterology 2003, 125, 1105-1113. [CrossRef]

8. Dewhirst, F.E.; Chen, T.; Izard, J.; Paster, B.J.; Tanner, A.C.; Yu, W.H.; Lakshmanan, A.; Wade, W.G. The human oral microbiome. J. Bacteriol. 2010, 192, 5002-5017. [CrossRef]

9. Fernandez-Feo, M.; Wei, G.; Blumenkranz, G.; Dewhirst, F.E.; Schuppan, D.; Oppenheim, F.G.; Helmerhorst, E.J. The cultivable human oral gluten-degrading microbiome and its potential implications in coeliac disease and gluten sensitivity. Clin. Microbiol. Infect. 2013, 19, E386-E394. [CrossRef]

10. Stearns, J.C.; Lynch, M.D.; Senadheera, D.B.; Tenenbaum, H.C.; Goldberg, M.B.; Cvitkovitch, D.G.; Croitoru, K.; Moreno-Hagelsieb, G.; Neufeld, J.D. Bacterial biogeography of the human digestive tract. Sci. Rep. 2011, 1, 170. [CrossRef]

11. Zamakhchari, M.; Wei, G.; Dewhirst, F.; Lee, J.; Schuppan, D.; Oppenheim, F.G.; Helmerhorst, E.J. Identification of Rothia bacteria as gluten-degrading natural colonizers of the upper gastro-intestinal tract. PLoS ONE 2011, 6, e24455. [CrossRef]

12. Ou, G.; Hedberg, M.; Horstedt, P.; Baranov, V.; Forsberg, G.; Drobni, M.; Sandstrom, O.; Wai, S.N.; Johansson, I.; Hammarstrom, M.L.; et al. Proximal small intestinal microbiota and identification of rod-shaped bacteria associated with childhood celiac disease. Am. J. Gastroenterol. 2009, 104, 3058-3067. [CrossRef] [PubMed]

13. Ramanan, P.; Barreto, J.N.; Osmon, D.R.; Tosh, P.K. Rothia bacteremia: A 10-year experience at Mayo Clinic, Rochester, Minnesota. J. Clin. Microbiol. 2014, 52, 3184-3189. [CrossRef] [PubMed]

14. Tian, N.; Wei, G.; Schuppan, D.; Helmerhorst, E.J. Effect of Rothia mucilaginosa enzymes on gliadin (gluten) structure, deamidation, and immunogenic epitopes relevant to celiac disease. Am. J. Physiol. Gastrointest. Liver Physiol. 2014, 307, G769-G776. [CrossRef] [PubMed]

15. Wei, G.; Tian, N.; Siezen, R.; Schuppan, D.; Helmerhorst, E.J. Identification of food-grade subtilisins as gluten-degrading enzymes to treat celiac disease. Am. J. Physiol. Gastrointest. Liver Physiol. 2016, 311, G571-G580. [CrossRef] [PubMed]

16. Helmerhorst, E.J.; Wei, G. Experimental Strategy to Discover Microbes with Gluten-degrading Enzyme Activities. Proc. Spie Int. Soc. Opt. Eng. 2014, 9112. [CrossRef] 
17. Wei, G.; Tian, N.; Valery, A.C.; Zhong, Y.; Schuppan, D.; Helmerhorst, E.J. Identification of Pseudolysin (lasB) as an Aciduric Gluten-Degrading Enzyme with High Therapeutic Potential for Celiac Disease. Am. J. Gastroenterol. 2015, 110, 899-908. [CrossRef]

18. Osman, A.A.; Uhlig, H.H.; Valdes, I.; Amin, M.; Mendez, E.; Mothes, T. A monoclonal antibody that recognizes a potential coeliac-toxic repetitive pentapeptide epitope in gliadins. Eur. J. Gastroenterol. Hepatol. 2001, 13, 1189-1193. [CrossRef]

19. White, L.E.; Bannerman, E.; Gillett, P.M. Coeliac disease and the gluten-free diet: A review of the burdens; factors associated with adherence and impact on health-related quality of life, with specific focus on adolescence. J. Hum. Nutr. Diet. 2016, 29, 593-606. [CrossRef]

20. Catassi, C.; Fabiani, E.; Iacono, G.; D'Agate, C.; Francavilla, R.; Biagi, F.; Volta, U.; Accomando, S.; Picarelli, A.; De Vitis, I.; et al. A prospective, double-blind, placebo-controlled trial to establish a safe gluten threshold for patients with celiac disease. Am. J. Clin. Nutr. 2007, 85, 160-166. [CrossRef]

21. Shan, L.; Marti, T.; Sollid, L.M.; Gray, G.M.; Khosla, C. Comparative biochemical analysis of three bacterial prolyl endopeptidases: Implications for coeliac sprue. Biochem. J. 2004, 383, 311-318. [CrossRef] [PubMed]

22. Bethune, M.T.; Khosla, C. Oral enzyme therapy for celiac sprue. Methods Enzym. 2012, 502, $241-271$. [CrossRef]

23. Khosla, C. Celiac Disease: Lessons for and from Chemical Biology. ACS Chem. Biol. 2017, 12, 1455-1459. [CrossRef] [PubMed]

24. Ehren, J.; Moron, B.; Martin, E.; Bethune, M.T.; Gray, G.M.; Khosla, C. A food-grade enzyme preparation with modest gluten detoxification properties. PLoS ONE 2009, 4, e6313. [CrossRef] [PubMed]

25. Gass, J.; Bethune, M.T.; Siegel, M.; Spencer, A.; Khosla, C. Combination enzyme therapy for gastric digestion of dietary gluten in patients with celiac sprue. Gastroenterology 2007, 133, 472-480. [CrossRef]

26. Wei, G.; Helmerhorst, E.J.; Darwish, G.; Blumenkranz, G.; Schuppan, D. Gluten Degrading Enzymes for Treatment of Celiac Disease. Nutrients 2020, 12, 2095. [CrossRef]

27. Krishnareddy, S.; Stier, K.; Recanati, M.; Lebwohl, B.; Green, P.H. Commercially available glutenases: A potential hazard in coeliac disease. Ther. Adv. Gastroenterol. 2017, 10, 473-481. [CrossRef]

28. Jose, N.M.; Bunt, C.R.; Hussain, M.A. Comparison of Microbiological and Probiotic Characteristics of Lactobacilli Isolates from Dairy Food Products and Animal Rumen Contents. Microorganisms 2015, 3, 198-212. [CrossRef]

29. Padmanabhan, P.; Grosse, J.; Asad, A.B.; Radda, G.K.; Golay, X. Gastrointestinal transit measurements in mice with 99mTc-DTPA-labeled activated charcoal using NanoSPECT-CT. EJNMMI Res. 2013, 3, 60. [CrossRef]

30. Rizzello, C.G.; De Angelis, M.; Di Cagno, R.; Camarca, A.; Silano, M.; Losito, I.; De Vincenzi, M.; De Bari, M.D.; Palmisano, F.; Maurano, F.; et al. Highly efficient gluten degradation by lactobacilli and fungal proteases during food processing: New perspectives for celiac disease. Appl. Environ. Microbiol. 2007, 73, 4499-4507. [CrossRef]

31. Klausen, B. Microbiological and immunological aspects of experimental periodontal disease in rats: A review article. J. Periodontol. 1991, 62, 59-73. [CrossRef] [PubMed]

32. Tanner, A. Microbial etiology of periodontal diseases. Where are we? Where are we going? Curr. Opin. Dent. 1992, 2, 12-24. [PubMed]

33. Watanabe, K. Prepubertal periodontitis: A review of diagnostic criteria, pathogenesis, and differential diagnosis. J. Periodontal. Res. 1990, 25, 31-48. [CrossRef] [PubMed]

34. Sassone, L.M.; Fidel, R.; Faveri, M.; Fidel, S.; Figueiredo, L.; Feres, M. Microbiological evaluation of primary endodontic infections in teeth with and without sinus tract. Int. Endod. J. 2008, 41, 508-515. [CrossRef]

35. Caminero, A.; Galipeau, H.J.; McCarville, J.L.; Johnston, C.W.; Bernier, S.P.; Russell, A.K.; Jury, J.; Herran, A.R.; Casqueiro, J.; Tye-Din, J.A.; et al. Duodenal Bacteria From Patients With Celiac Disease and Healthy Subjects Distinctly Affect Gluten Breakdown and Immunogenicity. Gastroenterology 2016, 151, 670-683. [CrossRef]

36. Schuppan, D.; Gisbert-Schuppan, K. Wheat Syndromes: How Wheat, Gluten and ATI Cause Inflammation, IBS and Autoimmune Diseases; Springer: Cham, Germany, 2019; 19p.

37. Wilkens, S. Structure and mechanism of ABC transporters. F1000Prime Rep. 2015, 7, 14. [CrossRef]

38. Ottesen, M.; Spector, A. A comparison of two proteinases from Bacillus subtilis. C. R. Trav. Lab. Carlsberg 1960, 32, 63-74. 
39. Dressman, J.B. Comparison of canine and human gastrointestinal physiology. Pharm. Res. 1986, 3, $123-131$. [CrossRef]

Publisher's Note: MDPI stays neutral with regard to jurisdictional claims in published maps and institutional affiliations.

(C) 2020 by the authors. Licensee MDPI, Basel, Switzerland. This article is an open access article distributed under the terms and conditions of the Creative Commons Attribution (CC BY) license (http://creativecommons.org/licenses/by/4.0/). 